\title{
Evaluation of Corrosion Protection of Self-Healing Coatings Containing Tung and Copaiba Oil Microcapsules
}

\author{
Nicolas Augusto Paolini $\mathbb{D}^{1},{ }^{1}$ Alexandre Gonçalves Cordeiro Neto ${ }^{(D)}{ }^{1}$ \\ Alana Cristine Pellanda $\left(\mathbb{D},{ }^{1}\right.$ Agne Roani de Carvalho Jorge ${ }^{D},{ }^{1}$ Bryan de Barros Soares $\mathbb{D}^{1}{ }^{1}$ \\ João Batista Floriano $\mathbb{D},{ }^{2}$ Marcos Antonio Coelho Berton $\mathbb{D}^{1},{ }^{1}$ Poornima Vijayan $\mathbf{P} \mathbb{D},{ }^{3}$ \\ and Sabu Thomas $(\mathbb{D})^{4,5,6}$ \\ ${ }^{1}$ Senai Innovation Institute for Electrochemistry, Av. Comendador Franco 1341, Curitiba, Brazil \\ ${ }^{2}$ Chemistry and Biology Department, Technological Federal University of Paraná, R. Dep. Heitor Alencar Furtado 5000, \\ Curitiba, Brazil \\ ${ }^{3}$ Sree Narayana College for Women (Affiliated to University of Kerala), 691001, Kollam, Kerala, India \\ ${ }^{4}$ International and Inter University Centre for Nanoscience and Nanotechnology, Mahatma Gandhi University, Kottayam, \\ Kerala, India \\ ${ }^{5}$ School of Chemical Sciences, Mahatma Gandhi University, Kottayam, Kerala, India \\ ${ }^{6}$ School of Energy Materials, Mahatma Gandhi University, Kottayam, Kerala, India \\ Correspondence should be addressed to Alexandre Gonçalves Cordeiro Neto; alexandre.neto@sistemafiep.org.br
}

Received 22 November 2020; Revised 28 January 2021; Accepted 11 February 2021; Published 4 March 2021

Academic Editor: Zhi Li

Copyright ( $\odot 2021$ Nicolas Augusto Paolini et al. This is an open access article distributed under the Creative Commons Attribution License, which permits unrestricted use, distribution, and reproduction in any medium, provided the original work is properly cited.

\begin{abstract}
The objective of the current research is to evaluate and compare the corrosion protection efficiency of the microcapsules containing tung oil and copaiba oil using stereoscopic images, electrochemical tests, open circuit potential (OCP), and polarization curves (Tafel analysis). Carbon steel plates were painted with three different coating systems: (a) a coating system with an automotive primer which served as the control, (b) a coating system with microcapsules containing $3 \%$ tung oil, and (c) a coating system with microcapsules containing $3 \%$ copaiba oil. A crosscut was performed using a scalpel on the coating surfaces to promote the release of the oils, and after drying, electrochemical cells were assembled using electrolyte $3 \% \mathrm{NaCl}$. From OCP analyses, it was verified that the coating system containing tung oil loaded microcapsules obtained more positive final values than the control system and the coating system containing copaiba oil loaded microcapsules. The stereoscope images corroborate the OCP results, and the polarization curve analyses also indicated that the microcapsules containing tung oil offer better corrosion protection than the other systems studied.
\end{abstract}

\section{Introduction}

The excessive corrosion of metals through structural degradation, chemical reactions, and wear deteriorates their performance and makes them unsuitable for use [1]. The failure of structures and equipment caused by corrosion generates a huge repair or replacement cost, in addition to safety issues. According to data between 2013 and 2015, global costs related to corrosion are estimated at US\$ 2.5 trillion annually, representing about $3.4 \%$ of the world's gross domestic product (GDP) [2]. There are several ways to reduce corrosion and, consequently, increase the service life of those metals. The most common way is to apply organic coatings, which are paints or varnishes that create a barrier to corrosive processes in harsh environments [3]. However, this type of protection becomes ineffective during physicalchemical processes. For instance, ultraviolet and infrared radiations begin to alter the properties of the coating, making 
it susceptible to failures, cracks, or microcracks. Once a crack develops on the coating, corrosive species such as water and salts in the corrosive medium may permeate through the coating until they reach the metallic substrate. Once corrosion has been triggered in the material, the coating would no longer be able to protect the damaged area [3]. One of the latest corrosion protection strategies is the use of selfregenerating coatings, called self-healing coatings, which can repair the damaged surface of the substrate without any human interference [4].

Examples of self-healing coatings include those containing complexes of polyelectrolytes, malleable polymers, and healing agents encapsulated in nano/microcapsules [5-7]. The capsules used to load the healing agents are either polymeric or inorganic in nature. Such micro- or nanocapsules are usually loaded with resins, corrosion inhibitors, and drying oils, which would be released by triggers such as $\mathrm{pH}$ changes, ion exchange processes, or mechanical damage $[8,9]$. Figure 1 shows an illustration of a microcapsule, in which the material of interest is retained in the nucleus of the microcapsule (core) and protected by the structure of the wall (shell).

The use of natural oils as core materials in microcapsules is of great significance in the protection of metal surfaces from corrosion. In this case, the cure reaction occurs through the oxidation of double bonds in natural oils by atmospheric oxygen, making them a green alternative since they do not need any external catalyst to cure the oil [4, 10-13]. The popular natural oils used for this purpose are tung oil [14], linseed oils [15], neem oil [16], etc.

However, there is no report on a comparison between coatings containing microcapsules that encapsulated different natural oils, to assess which of the oils has a better effect against corrosion. The present study is aimed at comparing qualitatively the anticorrosion protection ability of two different drying oils (tung oil and copaiba oil) encapsulated in poly(urea-formaldehyde) (PUF) microcapsules in smart coatings. Intelligent coatings based on drying oil encapsulated in PUF microcapsules and a polyesterbased automotive primer have been assessed for their selfhealing efficiency using optical analysis and electrochemical tests.

\section{Experimental}

2.1. Materials and Synthesis of Microcapsules. Urea, ammonium chloride, sodium chloride, resorcinol, sodium dodecyl sulfate (SDS), sodium hydroxide, poly(ethylene-alt-maleic anhydride) (EMA) with a molecular weight of 100,000 to $500,000 \mathrm{~g} \cdot \mathrm{mol}^{-1}$, 1-octanol, tung oil, and copaiba oil were obtained from Sigma-Aldrich. Cyclohexane and isopropyl alcohol were obtained from Dynamics. Aqueous formaldehyde solution $37 \mathrm{wt} \%$ was obtained from J.T.Baker. Triton X-100 was obtained from Vetec. Polyurethane sealant adhesive was obtained from Solufix. Corrosion tests were carried out using 1020 carbon steel specimens with dimensions of $150 \times 100 \times 3 \mathrm{~mm}(\mathrm{BS} 1)$ and an automotive primer based on polyester. All reagents were used as received without further purification.

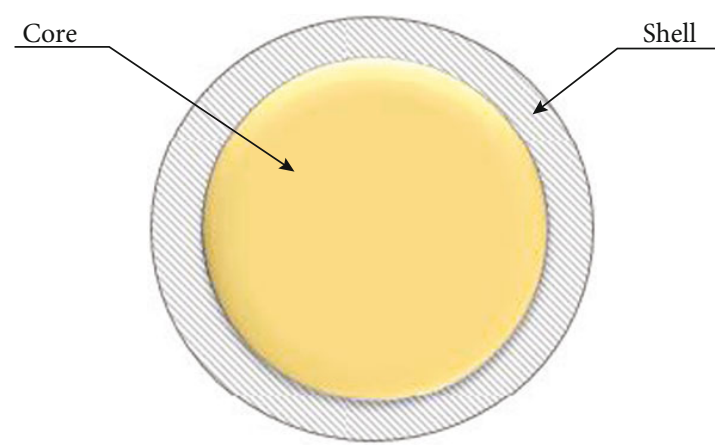

FigURE 1: Illustration of a core-shell microcapsule.

Poly(urea-formaldehyde) microcapsules containing tung oil or copaiba oil have been prepared according to Neto et al. in 2020 [17]. Poly(urea-formaldehyde) microcapsules containing either tung oil or copaiba oil were synthesized via in situ polymerization in an oil-in-water emulsion. In a beaker, $5.0 \mathrm{~g}$ of urea, $0.5 \mathrm{~g}$ of ammonium chloride, and $0.5 \mathrm{~g}$ of resorcinol were dissolved in $250 \mathrm{~mL}$ of $0.5 \mathrm{wt} \%$ aqueous EMA solution under stirring and at room temperature $\left(20 \pm 2^{\circ} \mathrm{C}\right)$. The $\mathrm{pH}$ of the mixture was adjusted to 3.5 using an aqueous sodium hydroxide solution $\left(1.0 \mathrm{~mol} \cdot \mathrm{L}^{-1}\right)$. After $\mathrm{pH}$ adjustment, $0.2 \mathrm{~g}$ of SDS and $0.2 \mathrm{~g}$ of Triton X-100 were added to the solution. After the dissolution of the surfactants, the $\mathrm{pH}$ was adjusted to 3.5 again.

The reaction medium was placed in a thermostatic bath (Tecnal TE-184) and coupled to a mechanical stirrer (Fisatom 713D). To prevent foaming, approximately 5 drops of 1-octanol were added to the solution. Under stirring at a speed of $1200 \mathrm{rpm}, 35.0 \mathrm{~g}$ of tung oil or copaiba oil was added dropwise to the solution to prepare the emulsion. The emulsion was kept under stirring for 30 minutes for stabilization. Then, $11.5 \mathrm{~mL}$ of aqueous formaldehyde solution (37\%) was added, and the temperature was gradually increased to about $55 \pm 1^{\circ} \mathrm{C}$. Stirring was continued, and the reaction proceeded for 4 hours. The suspension containing the microcapsules was cooled to room temperature $\left(20 \pm 2^{\circ} \mathrm{C}\right)$, and then the microcapsules were taken to the purification step. Empty microcapsules were synthesized based on the same procedure but without the addition of oil.

The microcapsule purification procedure was performed in two steps: washing and sieving, both in a batch. In the washing step, filtration was performed using a Büchner funnel under reduced pressure. The microcapsules were washed with $200 \mathrm{~mL}$ ultrapure water, $80 \mathrm{~mL}$ isopropyl alcohol, and $40 \mathrm{~mL}$ cyclohexane followed by drying at room temperature $\left(20 \pm 2^{\circ} \mathrm{C}\right)$. In the second stage, the dried microcapsules were sieved on a sieve shaker using three 180, 90, and $60 \mu \mathrm{m}$ aperture sieves.

2.2. Characterization of the Prepared Microcapsules. The synthesized microcapsules containing tung oil or copaiba oil were characterized by optical microscopy (OM) to evaluate parameters such as morphology, size regularity, and presence of residual material. Aliquots of the material were deposited on glass slides and were observed in a Zeiss Axio Imager Z2m Optical Microscope, using the image manipulation 
software AxioVision SE64. Aliquots of crude material and microcapsules were analyzed after washing and filtration. The objective was used with a magnification of $5 x$. Scanning electron microscopy analyses were performed using a Hitachi microscope (TM3000) to evaluate the morphology of the microcapsules, in addition to structural integrity and roughness. Infrared analyses with Fourier transform were performed to confirm the encapsulation of the oils. The analyses were performed using the Bruker Vertex 70 with ATR mode in the range of 400 to $4000 \mathrm{~cm}^{-1}$. Particle size analyses were performed by laser granulometry using the Microtrac model S3500 Bluewave granulometer and the Microtrac Bluewave software. The analysis was carried out in a wet method using deionized water as the medium, in which the microcapsules were previously submitted to the equipment's ultrasound process for 3 minutes for the dispersion of agglomerates.

2.3. Preparation of Coating Samples. Three different coating samples were prepared for analysis. The control coating was prepared by adding 50\% of the polyester-based automotive primer to the $10 \%(w / w)$ xylene-based diluent according to the recommended proportion by the manufacturer. The mixture was maintained at $250 \mathrm{rpm}$ on a mechanical stirrer (Fisatom 713D) for $10 \mathrm{~min}$ for complete homogenization of the paint.

For the other systems, before the incorporation of the diluent in the primer, microcapsules of tung oil or copaiba oil were added manually in the diluent, in a proportion of $3 \%(w / w)$, to later incorporate it into the primer. These systems were named MCOT and MCOC, respectively. After adding the diluent with microcapsules in the ink, the system was maintained at $250 \mathrm{rpm}$ in a mechanical stirrer (Fisatom 713D) for $10 \mathrm{~min}$ for total homogenization.

The coatings were applied to blasted and degreased 1020 carbon steel substrates with dimensions of $150 \times$ $100 \times 3 \mathrm{~mm}^{3}$ inside an automotive paint booth using a 1.8 spray gun (SATAjet $100 \mathrm{~B}$ ), and two coats were applied, with a 5-minute interval between coats. After painting, the specimens remained inside the painting booth at a temperature of $25^{\circ} \mathrm{C}$ for approximately 24 hours for drying. They were then taken to a bench at room temperature $\left(\sim 20 \pm 2^{\circ} \mathrm{C}\right)$, where they remained for an additional 72 hours until complete drying.

The morphology of the coating surface was viewed using a Zeiss SteREO Discovery V.12 stereoscope with the aid of image manipulation software AxioVision SE64. The brightness of the applied film was determined using a brightness meter (micro-TRI-gloss $\mu, \mathrm{BYK}$ ), analyzing a triplicate of samples, and they were classified according to their brightness range. The thickness of the dry applied coating was determined by the magnetic field attenuation method using the byko-test 8500 (BYK) equipment.

\subsection{Analysis of Corrosion Resistance and Self-Healing Action.} The study of corrosion protection and self-healing action was performed using an electrochemical cell consisting of three electrodes, made on the specimens, based on the contraption proposed by Cordeiro Neto et al. in 2020 [17]. For this,
$40 \mathrm{~mm}$ long cut-off defects were caused using a scalpel blade over one region of each sample, and the samples remained at room temperature $\left(20 \pm 2^{\circ} \mathrm{C}\right)$ for 24 hours for healing. These defects were made to cause the microcapsules to rupture mechanically and to force the release of tung oil and copaiba oil, simulating a real microfissure situation under the microcapsule shell. In each defective region, a cylindrical compartment made of $17 \mathrm{~cm}^{2}$ polypropylene was fixed, this being the active area of the working electrode. To make the electrochemical cell, $40 \mathrm{~mL}$ of electrolyte and $3.5 \mathrm{wt} \% \mathrm{NaCl}$ were added. The reference electrode used was $\mathrm{Ag} / \mathrm{AgCl} / \mathrm{KCl}$ (sat.) (Metrohm), and the counter electrode served as the platinum net and the exposed sample served as the working electrode.

OCP tests were carried out up to 240 hours after the solution came into contact with the coating, and measurements were taken at $1,2,4,8,24,48,72,144,170,192$, 216 , and 240 hours. The first hour of immersion was measured constantly. A Metrohm Multi Autolab Cabinet MAC80058 potentiostat was used for the experiment, and NOVA 1.11 software was used for data analysis.

For the analysis of polarization curves, a carbon steel plate was used as the working electrode (WE), the silver/silver chloride electrode with a saturated $\mathrm{KCl}(\mathrm{Ag} / \mathrm{AgCl}(\mathrm{KCl}$ (sat.))) was used as the reference electrode (RE), and the platinum mesh was used as the counter electrode (CE). The analysis was carried out one hour after the solution came into contact with the coatings to stabilize the OCP. The scanning speed used was $1 \mathrm{mV} / \mathrm{s}$. The measurements started at $100 \mathrm{mV}$ below the OCP and ended at a fixed value of $-0.2 \mathrm{mV}$. The Metrohm Multi Autolab Cabinet MAC80058 potentiostat was used for the experiment, and NOVA 1.11 software was used for data analysis.

\section{Results and Discussions}

3.1. Characterization of Tung Oil Encapsulated in Microcapsules. The optical microscopy image of the raw material is shown in Figure 2(a). The image analysis shows that there was formation of microcapsules and the presence of a considerable amount of a residual polymer. The purification process by filtration and washing with solvents is aimed at removing this residual material existing at the end of the synthesis, and the microscopy analysis was performed to find out if there was any degradation of the microcapsules after washing. Figure 2(b) shows the optical microscopy image of the purified material. It is observed that the microcapsules are spherical, presenting a wall with characteristic roughness. It is also noted that the amount of residual material decreased and that there was no deterioration of the microcapsules after washing.

Figure 3 shows the SEM images of the tung oil microcapsules. It is observed that the microcapsules have a spherical morphology. The wall of the synthesized microcapsules is uniform and appears to have a coating of adhered poly(urea-formaldehyde) nanoparticles that cause this characteristic roughness.

The FTIR analysis of the prepared microcapsules is intended to chemically confirm the encapsulation of tung 


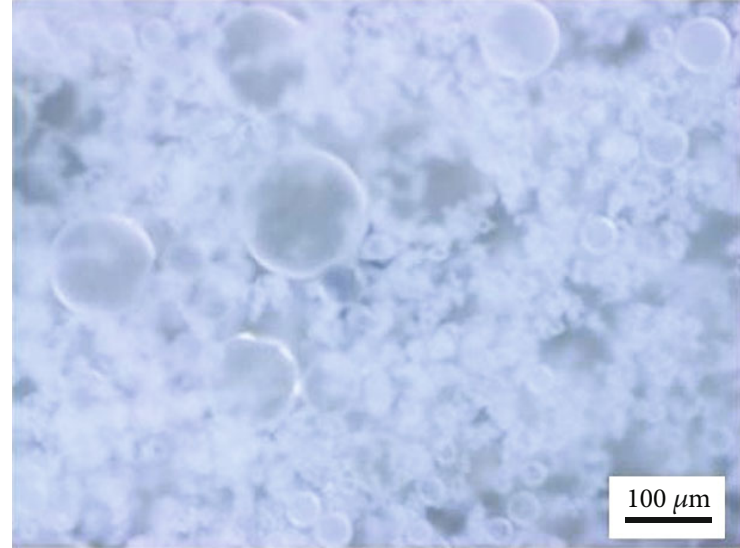

(a)

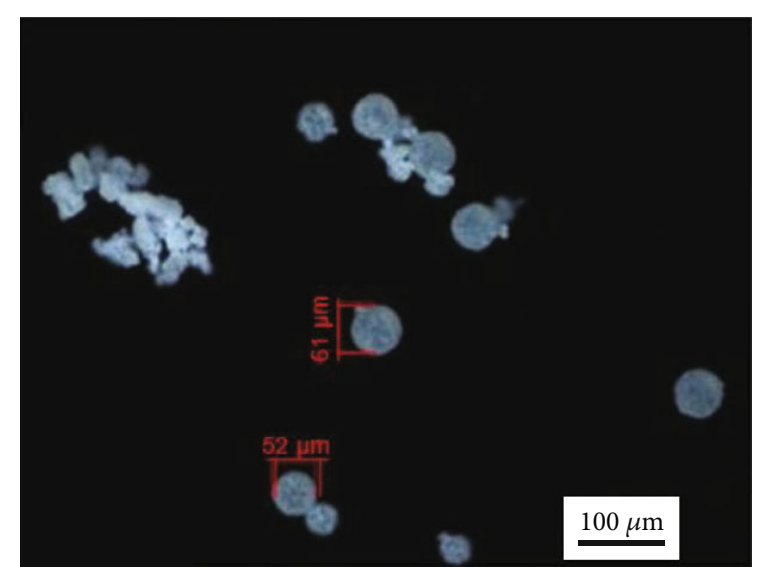

(b)

Figure 2: Optical microscopy images of tung oil microcapsules (a) raw material and (b) microcapsules after washing.

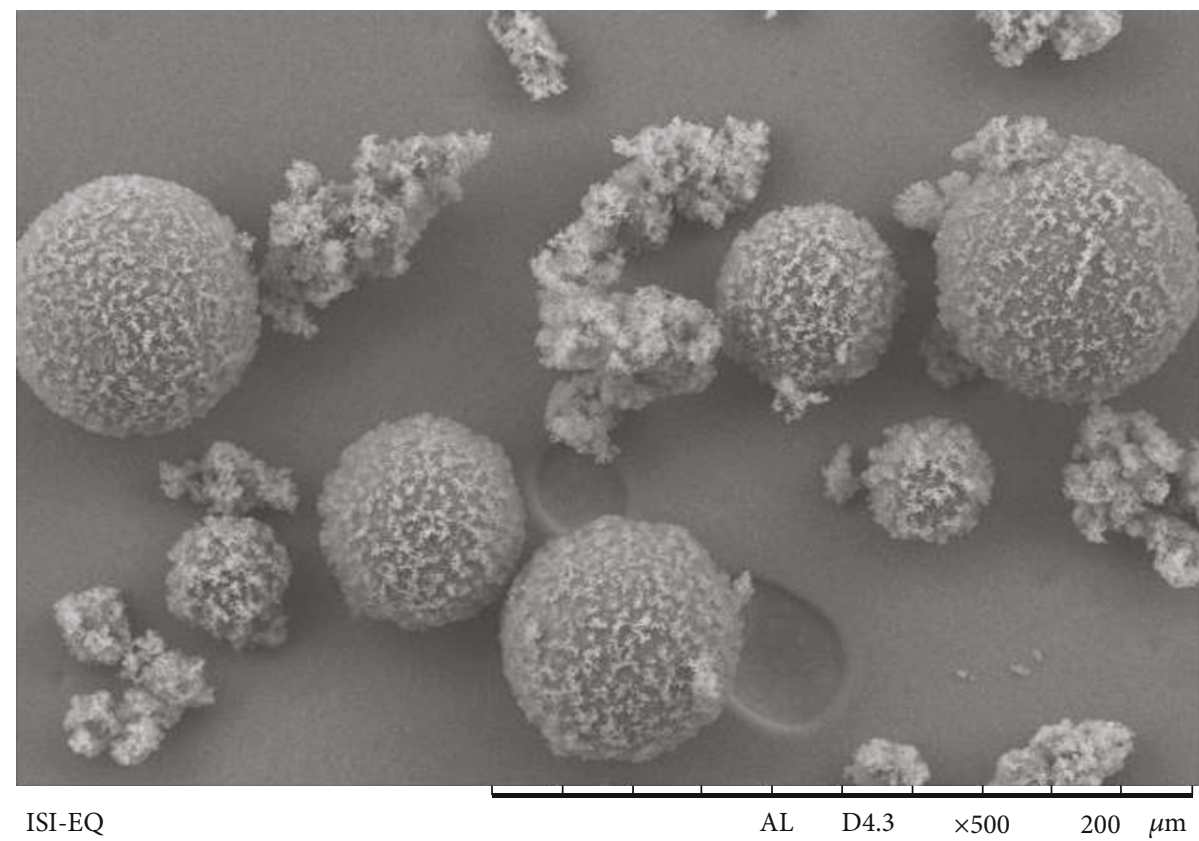

Figure 3: SEM images of tung oil microcapsules.

oil. To provide identification, the wall and core materials were analyzed separately, and the spectra were compared with the microcapsule spectrum. Figure 4 shows the FTIR spectra of microcapsules without tung oil, that is, only the wall material (PUF), the synthesized microcapsules (MCOT), and the core material (tung oil). The contribution of both the core material and the wall material in the spectrum of the microcapsules is evident. Upon analyzing the spectra of the wall material and MCOT, the presence of the bands between 3500 and $3200 \mathrm{~cm}^{-1}$ corresponding to the $\mathrm{O}-\mathrm{H}$ absorption band, the presence of the band at $1631 \mathrm{~cm}^{-}$ ${ }^{1}$ corresponding to the stretch $\mathrm{C}=\mathrm{O}$, and the presence of the band at $1552 \mathrm{~cm}^{-1}$ corresponding to the stretch $\mathrm{N}-\mathrm{H}$ are detected [18]. Comparing the spectrum of the core material with the MCOT spectrum, there is also a correla- tion between the spectra, due to the presence of the band at $2924 \mathrm{~cm}^{-1}$ corresponding to the $\mathrm{O}-\mathrm{H}$ stretch, the band at $2854 \mathrm{~cm}^{-1}$ corresponding to the $\mathrm{C}-\mathrm{H}$ stretch, and the band at $1741 \mathrm{~cm}^{-1}$ corresponding to the $\mathrm{C}=\mathrm{O}$ stretch $[19,20]$. From these correlations, it is possible to confirm the satisfactory encapsulation of the tung oil by the wall material of PUF.

To verify the size distribution of the synthesized microcapsules, laser particle size analysis was carried out. Figure 5 shows that the average diameter of the microcapsules is $24.66 \mu \mathrm{m}$ and that $95 \%$ of the microcapsules do not exceed the size of $50 \mu \mathrm{m}$.

3.2. Characterization of Copaiba Oil Encapsulated in Microcapsules. The optical microscopic images of the 


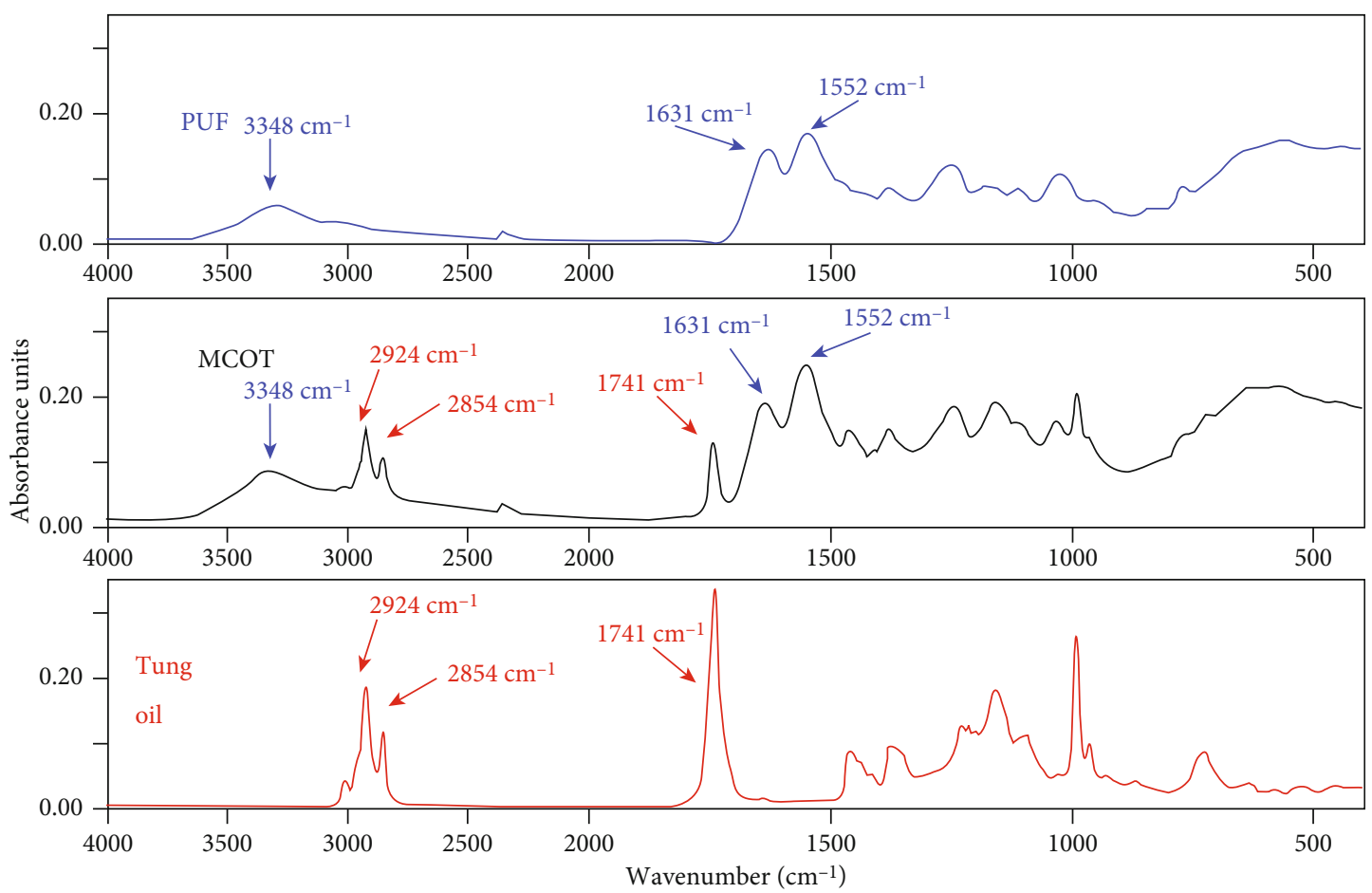

FIGURE 4: FTIR spectra of the wall material (poly(urea-formaldehyde)), the core material (tung oil), and the burst microcapsules.

\begin{tabular}{|c|c|}
\hline \multicolumn{2}{|c|}{ Percentiles } \\
\hline \%Tile & Size $(\mu \mathrm{m})$ \\
\hline 10.00 & 14.23 \\
\hline 20.00 & 17.68 \\
\hline 30.00 & 20.18 \\
\hline 40.00 & 22.44 \\
\hline 50.00 & 24.66 \\
\hline 60.00 & 27.08 \\
\hline 70.00 & 29.91 \\
\hline 80.00 & 33.76 \\
\hline 90.00 & 40.50 \\
\hline 95.00 & 48.14 \\
\hline
\end{tabular}

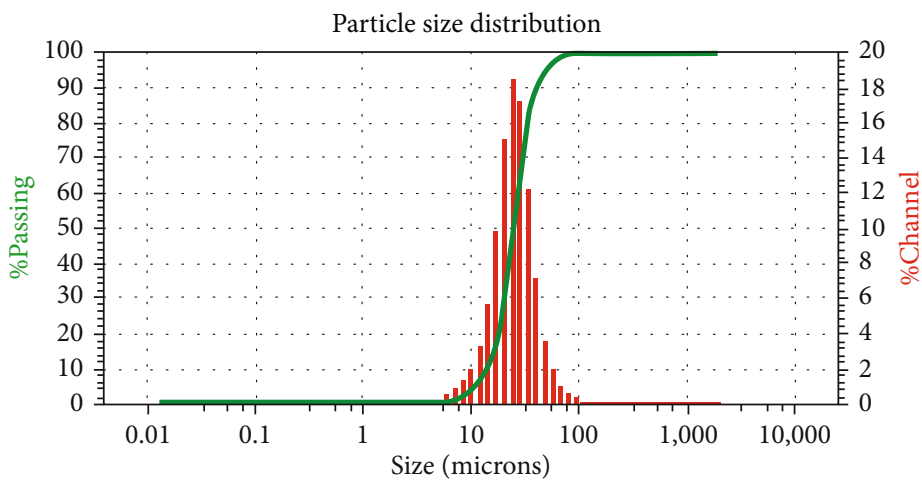

FIgURE 5: Particle size distribution chart for tung oil microcapsules.

synthesized copaiba oil encapsulated in microcapsules are shown in Figure 6. While Figure 6(a) shows the image of the raw material, Figure 6(b)shows the image of the purified material. It is observed that the microcapsules are spherical, having a wall with a roughness like that found in the tung oil encapsulated in microcapsules (Figure 2). After washing, there is an evident decrease in the residual material.

SEM analyses were performed to observe the morphology of the synthesized copaiba oil encapsulated in microcapsules (Figure 7). From the images, it is possible to verify that the microcapsules are spherical, with a morphology like that of tung oil encapsulated in microcapsules (Figure 3). The wall of the microcapsules appears to have a coating of adhered poly(urea-formaldehyde) nanoparticles. The existence of smaller agglomerated microcapsules is greater than that of the microcapsule sample containing encapsulated tung oil.
The morphological studies confirmed that the microcapsules are intact, without defects or holes, and have a morphology like that of tung oil encapsulated in microcapsules.

Figure 8 shows the FTIR spectra of the wall material (PUF), the synthesized microcapsules, and the core material (copaia oil). It is possible to observe the contribution of the spectra of both the core material and the wall material in the microcapsule spectrum; by initially analyzing only the spectra of the wall material and the MCOC, we see the correlation between the spectra due to the presence of the bands between 3500 and $3200 \mathrm{~cm}^{-1}$ corresponding to the $\mathrm{OH}$ absorption band, the band at $1631 \mathrm{~cm}^{-1}$ corresponding to the $\mathrm{C}=\mathrm{O}$ stretch, and the band at $1552 \mathrm{~cm}^{-1}$ corresponding to the $\mathrm{N}-\mathrm{H}$ stretch [18]. Comparing the spectrum of the core material with the MCOC spectrum, there is also a correlation between the spectra due to the presence of the band at 


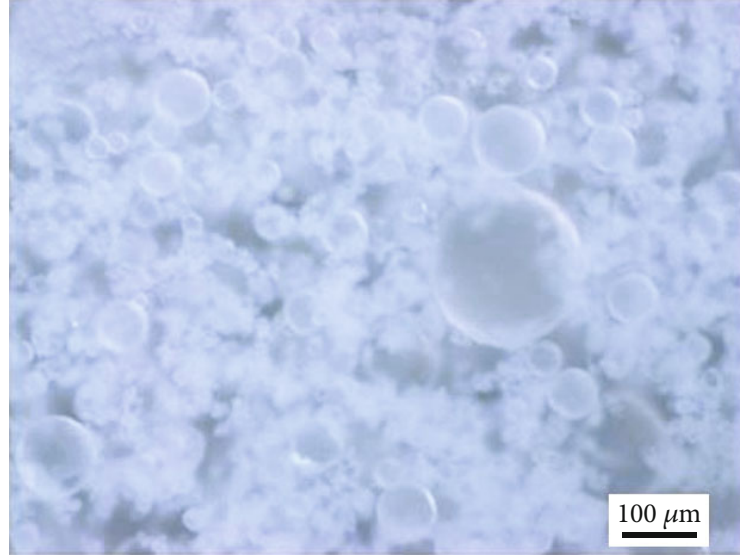

(a)

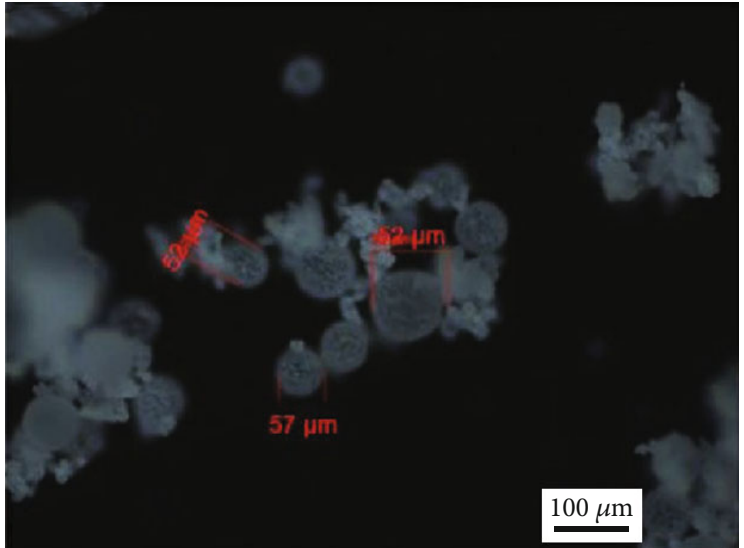

(b)

Figure 6: Optical microscopy images of copaiba oil microcapsules (a) raw material and (b) the material after washing.

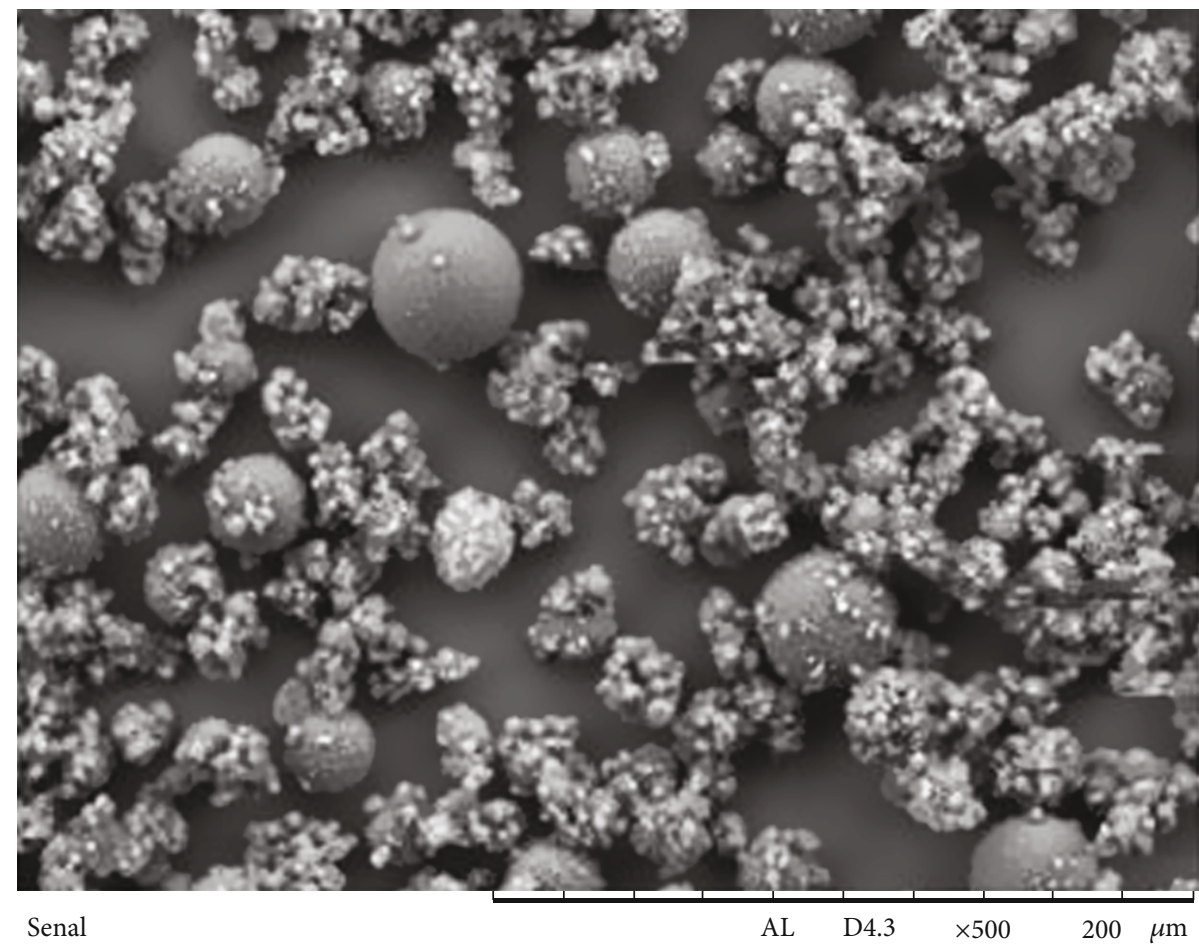

FIGURE 7: SEM images of copaiba oil microcapsules.

$2925 \mathrm{~cm}^{-1}$ corresponding to the $\mathrm{C}-\mathrm{H}$ stretch, the band at $1726 \mathrm{~cm}^{-1}$ corresponding to the $\mathrm{C}=\mathrm{O}$ stretch, and the band at $1446 \mathrm{~cm}^{-1}$ corresponding to the $\mathrm{C}-\mathrm{O}$ stretch [21]. Due to these correlations, it is confirmed that there was satisfactory encapsulation of the copaiba oil by the poly(urea-formaldehyde) wall material.

The results of the particle size laser analysis are shown in Figure 9. It is noticed that the average diameter of the microcapsules is close to the microcapsules of tung oil $(22.50 \mu \mathrm{m}$ against $24.66 \mu \mathrm{m})$. Also, it is observed that the maximum size of the microcapsules does not exceed the diameter of $50 \mu \mathrm{m}$.
3.3. Characterizations of the Coatings. Figure 10 shows the optical microscopy images of the surfaces of the control, MCOC, and MCOT plates. It is noted that the roughness of the plates containing microcapsules is greater than that of the control, and it is possible to observe that the roughness of the plate containing MCOT is greater than the plate containing MCOC, leading to the conclusion that the amount of capsules present in the ink is greater. This may indicate that the copaiba oil microcapsules have not completely resisted the paint application process, with the rupture of some microcapsules, or this may be related to a difference in the accommodation of the microcapsules in the coating. 


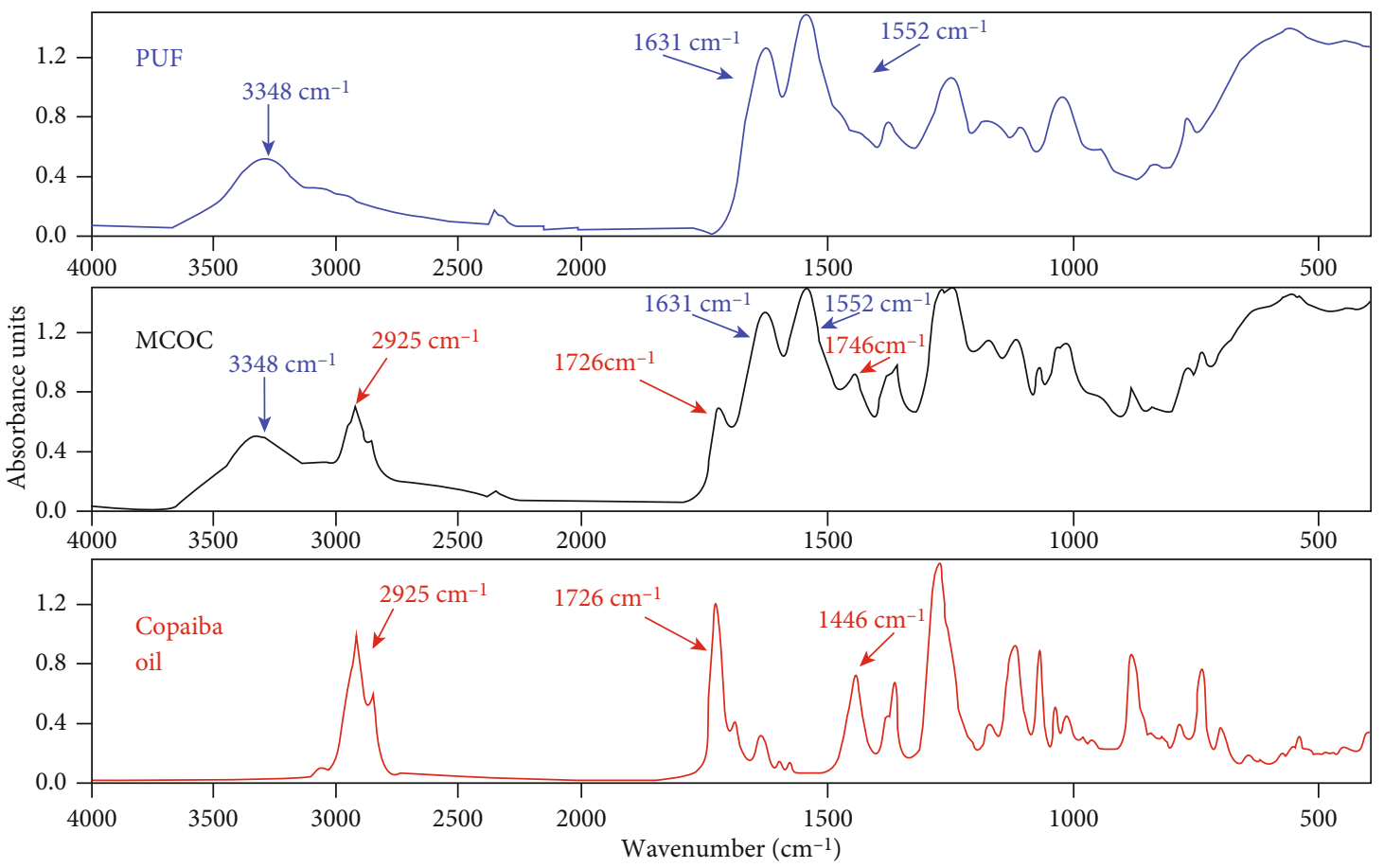

FIGURE 8: FTIR spectra of the wall material (poly(urea-formaldehyde), the core material (copaiba oil), and the burst microcapsules.

\begin{tabular}{|c|c|}
\hline \multicolumn{2}{|c|}{ Percentiles } \\
\hline \%Tile & Size $(\mu \mathrm{m})$ \\
\hline 10.00 & 15.62 \\
\hline 20.00 & 17.63 \\
\hline 30.00 & 19.28 \\
\hline 40.00 & 20.84 \\
\hline 50.00 & 22.50 \\
\hline 60.00 & 24.39 \\
\hline 70.00 & 26.76 \\
\hline 80.00 & 30.23 \\
\hline 90.00 & 36.91 \\
\hline 95.00 & 45.26 \\
\hline
\end{tabular}

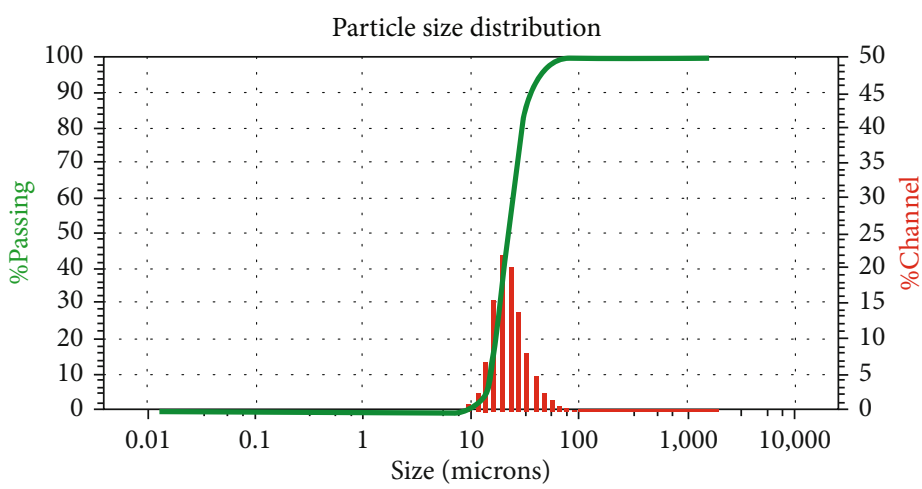

Figure 9: Particle size distribution chart of copaiba oil microcapsules.
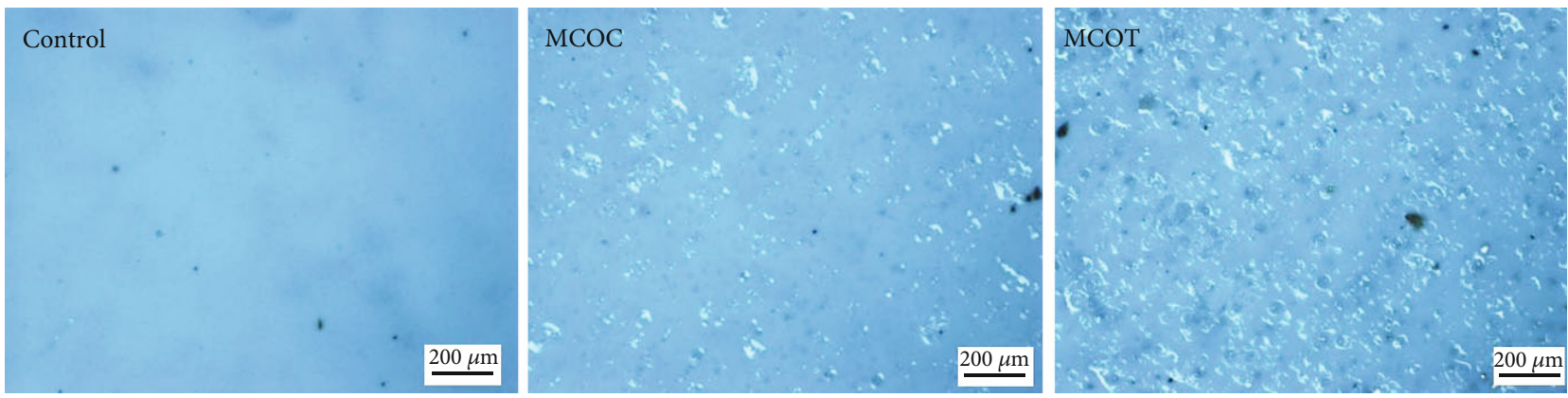

FIGURE 10: Optical microscopy images of the surfaces of the control, MCOC, and MCOT plates.

The copaiba microcapsules may have been positioned closer to the metallic substrate while the tung microcapsules may have been positioned at the top of the coating.
After curing the coating, thickness measurements were made to ensure that the applied coatings were of similar thickness. In all, ten measurements were made on the plates. 
TABLe 1: Dry film thickness $(\phi)$ analysis of applied samples.

\begin{tabular}{lc}
\hline Sample & $\phi(\mu \mathrm{m})$ \\
\hline Control & $47 \pm 3$ \\
MCOC & $47 \pm 2$ \\
MCOT & $45 \pm 3$ \\
\hline
\end{tabular}

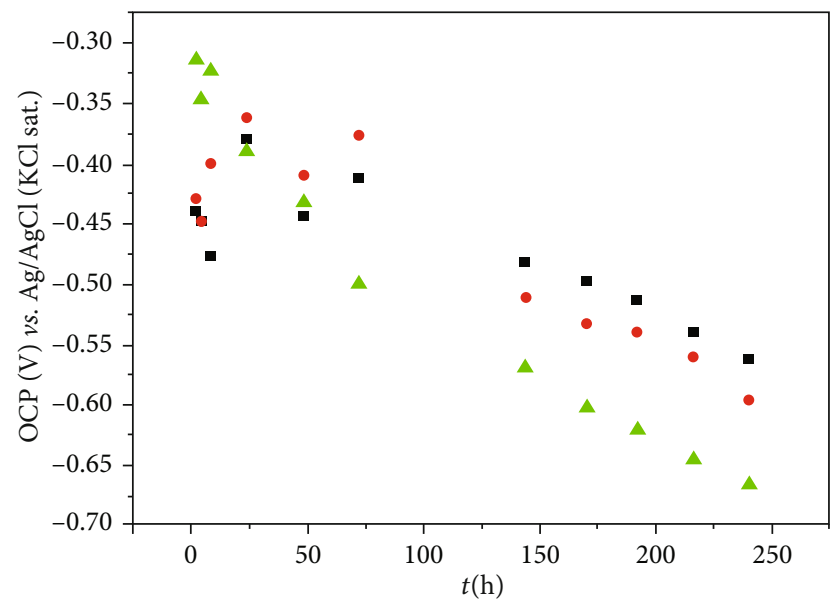

- MCOT

- Control

$\triangle \mathrm{MCOC}$

FIgure 11: Compilation of OCP data up to 240 hours: the measurements on the plate that contain (a) $3 \%(\mathrm{~m} / \mathrm{m})$ MCOT are represented by the black squares, (b) those that contain $3 \%(\mathrm{~m} / \mathrm{m})$ MCOC are represented by green triangles, and (c) the measurements of the control plate are represented by red dots.

The average values of the thickness $(\phi)$, as well as the respective standard deviations, are shown in Table 1. It is possible to observe that all plates were coated with a dry film of close thickness, demonstrating that the application was carried out satisfactorily.

\subsection{Electrochemical Characterization}

3.4.1. Evaluation of Open Circuit Potential (OCP). Figure 11 shows the OCP graphs as a function of time $(t)$ for the three systems studied. In the graph, the black points are the measurements of the plate containing $3 \%(w / w)$ of MCOT, the green points are those of the plate containing 3\% $(w / w)$ of MCOC, and the red points are those of the control plate.

As described by Souza et al. in 2005 [22], the OCP in metallic materials is equivalent to the corrosion potential, so when obtaining more positive values, it may indicate resistance to corrosion. In systems with self-healing properties obtained by incorporating microcapsules, when a defect occurs, there is a sudden decrease in potential and a gradual return to the passivation level indicating occurrence of selfregeneration [23]. For the tests, the coating was completely cured and, as in the systems where there was regeneration, this gradual return has already occurred, so the system will be more protected.
It can be observed that up to the period of 8 hours after adding the solution, the coating containing MCOC showed less negative OCP values than the control, and the coating containing MCOT showed itself to be more protective so far; however, over time, the MCOT coating shows more positive values among the three, indicating that it is the system with the best protection. In addition, over time, the MCOC system becomes worse than the control, with results far different from what was expected with the addition of microcapsules.

In order to understand this greater protection of the MCOC system at shorter times and the greater protection of the MCOT system at longer times, we compared the images of the damage done with the scalpel on the three plates at zero time and after drying in an oven. Figure 12 shows the optical microscopy images of the control, MCOC, and MCOT plates at both times.

It is possible to verify that in the control plate and in the plate containing MCOC, the risk was almost completely regenerated by the primer itself, demonstrating that the primer has a certain elasticity that was superior to the drying capacity of copaiba oil. This effect is different when compared to the plate containing MCOT, as it is observed that the damage was not covered by the paint, so it is believed that for this difference to occur, some component created a barrier preventing the return of the paint, and that component can precisely be the released tung oil that filled the risk. Due to the regeneration of the primer in the plate containing MCOC and adding this to the barrier effect that the addition of the microcapsules provides, it is believed that these combined factors caused the improvement of the observed OCP for the first hours of contact of the solution; however, over time the microcapsules proved inefficient.

For MCOTs, the system showed the best OCP values from 144 hours until the end of the experiment, showing the efficiency of tung oil in forming a protective barrier to inhibit the passage of the electrolyte and start the corrosive process and also in possibly stopping corrosive processes that start after several hours upon coming in contact with the electrolyte.

In order to compare the control system with systems containing microcapsules (in addition to the action of the drying oil), the action of inserting the microcapsules, which causes a barrier property to the primer (in addition to other influences that may cause it), should also be considered. Comparing with the control, the two systems containing microcapsules showed better results at different exposure times: the MCOC system for a few hours after contact with the solution and the MCOT system for longer times.

As a consideration when comparing the effect of the oils, the comparison should be made only between the two systems containing microcapsules, because this way it is possible to remove the influence of the insertion of the microcapsules. Analyzing the curves, it can be concluded that tung oil is more effective for the system, since in one application it is appreciated that the microcapsules improve the results for the entire exposure period, and not only for the first contact times. 


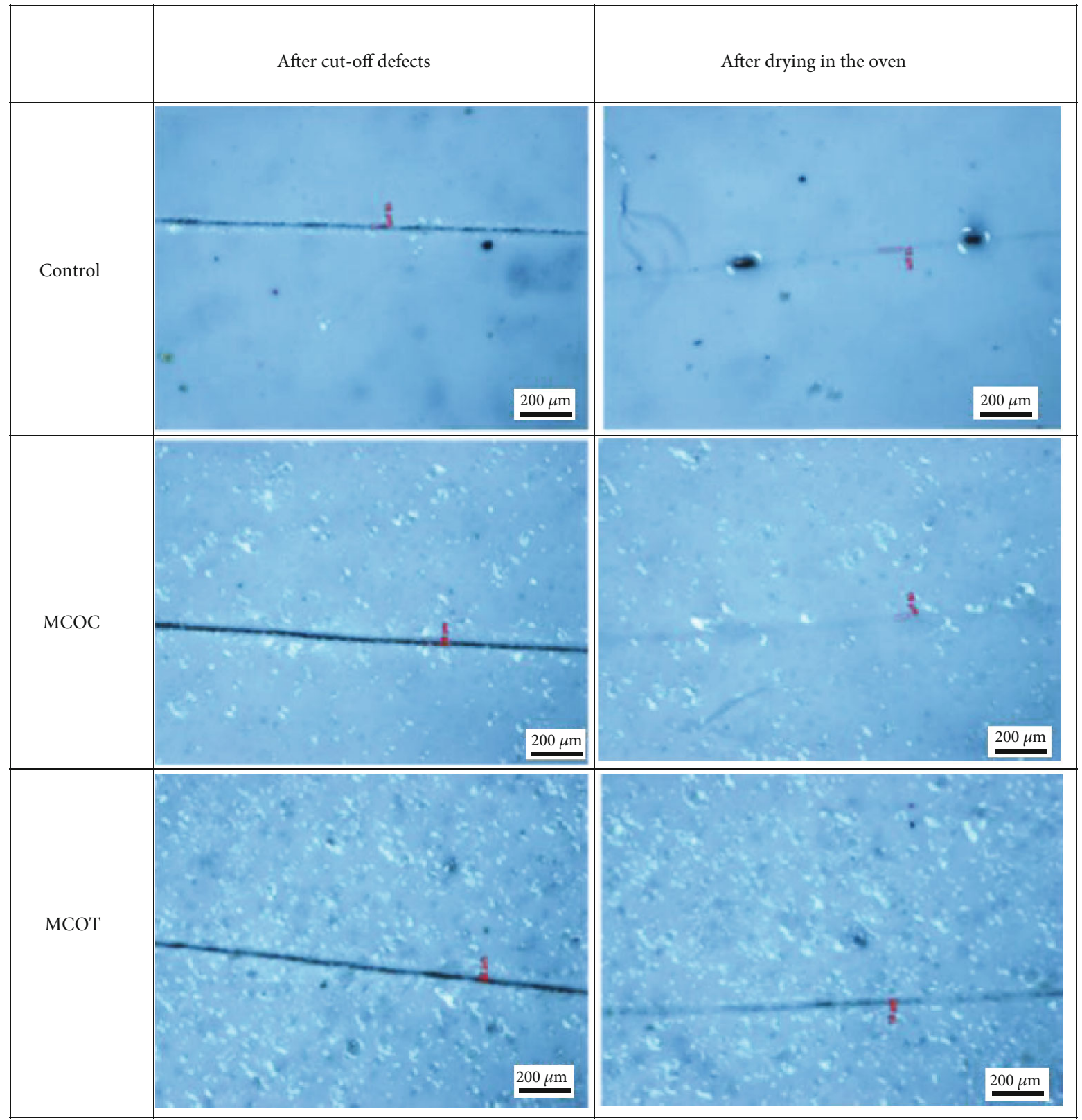

Figure 12: Optical microscopy images of the MCOC and MCOT control plates at the times after cutting and after the oven.

Parallel to the OCP analyses, stereoscopic images of the cells were taken at the same exposure times. The results of up to 24 hours of exposure to the electrolyte are shown in Figure 13, for the control, MCOC, and MCOT systems. It appears that the images of the three systems remain similar even up to 8 hours of exposure. After 4 more hours, there is a focus of corrosion, and after 8 more hours, the systems have two or three small points of corrosion. After 24 hours, a change is noted; the control system has two foci of corrosion at the ends of the site where the damage was done with the scalpel showing the formation of iron oxides. After 24 hours, the system containing MCOC presents several corrosion spots spread both in the delimitation of the risk and in other points, also presenting formation of iron oxides. In compensation, the system containing MCOT presents more con- tained spots of corrosion, and without the most intense coloring of the formed oxides.

The images of the control system, the MCOT system, and the MCOC system at the exposure times between 48 and 240 hours are shown in Figure 14. Between 48 and 72 hours of immersion, the differences between the systems become more highly expressed. The system containing MCOC has several points of corrosion along the cut and in other places of the cell. The control system also presents several points of corrosion, and the intensification of corrosion in the outbreaks presents at 24 hours, but visually, the corrosion is not as highly expressed when compared with the MCOC system. The MCOT system has the best resistance and corrosion inhibition for up to 72 hours, with more significant corrosion only at the center of the risk. 


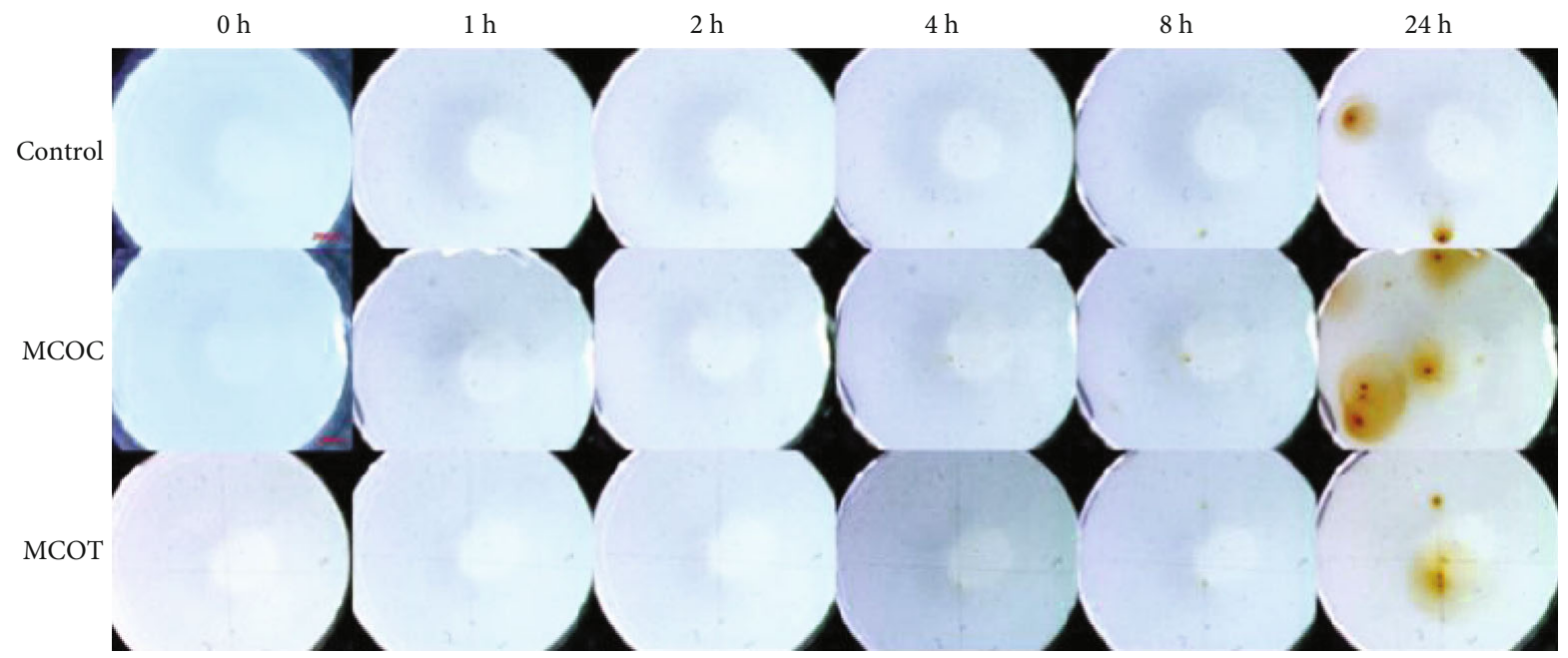

FIGURE 13: Control system, MCOT system, and MCOC system images up to 24 hours of electrolyte exposure.

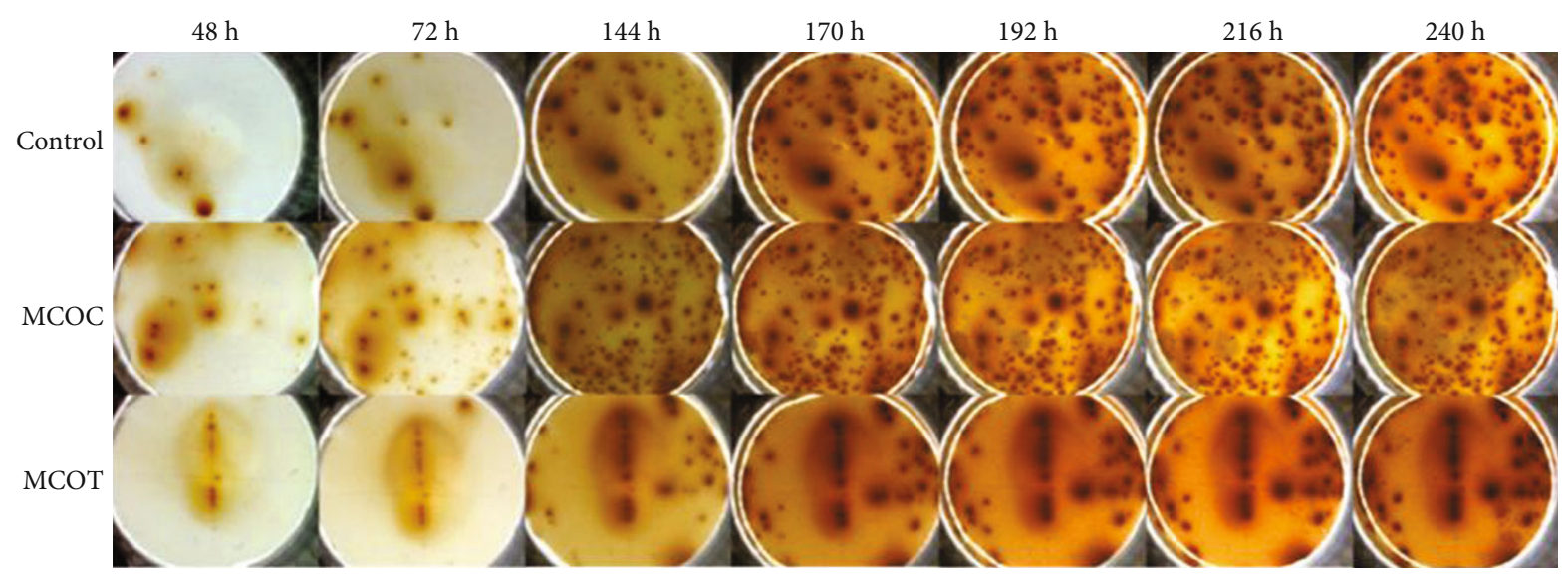

FIGURE 14: Control system, MCOT system, and MCOC system images with exposure hours between 48 and 240 hours.

After 144 hours, the MCOT system tends to have better protection than the other systems studied. The control system has numerous points of oxidation throughout the entire coating and in some points a very aggressive corrosion. In the MCOC system, in addition to the corrosion spots, it is observed that in some places there is a darkening of the primer, potentially indicating that the electrolyte has permeated the coating and is causing the coating to detach. This permeation of the electrolyte may be an explanation why the OCP of the MCOC system is the worst of the three systems in these analyses (144-240 hours), considering that in the other systems, this permeation is not observed. Finally, the MCOT system shows corrosion spots only along the scratch and at the ends of the cell.

From the images, it is concluded that for the visual analysis of electrochemical cells, the MCOT system is the most protective among those studied. This conclusion corroborates with the presented OCP data, in which the MCOT system had more positive OCP values than the others.

3.4.2. Polarization Curves. Figure 15 shows the polarization curves obtained from the control system, the MCOC system, and the MCOT system. Through the polarization curves, the two MCOC and MCOT systems have less corrosion potential than the control, with MCOT being the most positive, indicating that thermodynamically, these systems have less corrosion tendency [24]. After obtaining the polarization curves, the data were adjusted in the NOVA 1.11 software to obtain the data of corrosion potential $\left(E_{\text {corr }}\right)$, corrosion current density $\left(j_{\text {corr }}\right)$, corrosion rate $(\mathrm{CR})$, and polarization resistance $\left(R_{\mathrm{p}}\right)$. The compilation of this data for unpainted, control, MCOT, and MCOC systems is shown in Table 2.

Analyzing initially the data of the column of the corrosion potential $\left(E_{\text {corr }}\right)$, it is noticed that the values of the systems containing microcapsules are less negative than the control, with the MCOT system having the lowest negative value, and as explained previously, these less negative values indicate that thermodynamically, these systems are less prone to corrosion [24]. In the corrosion current density column $\left(j_{\text {corr }}\right)$, there is a considerable drop in the value caused by the addition of the MCOC and MCOT in the coating, with both systems presenting practically identical values. This decrease in current density indicates greater corrosion inhibition efficiency, as described by Pontes et al. in 2016 [25]. 


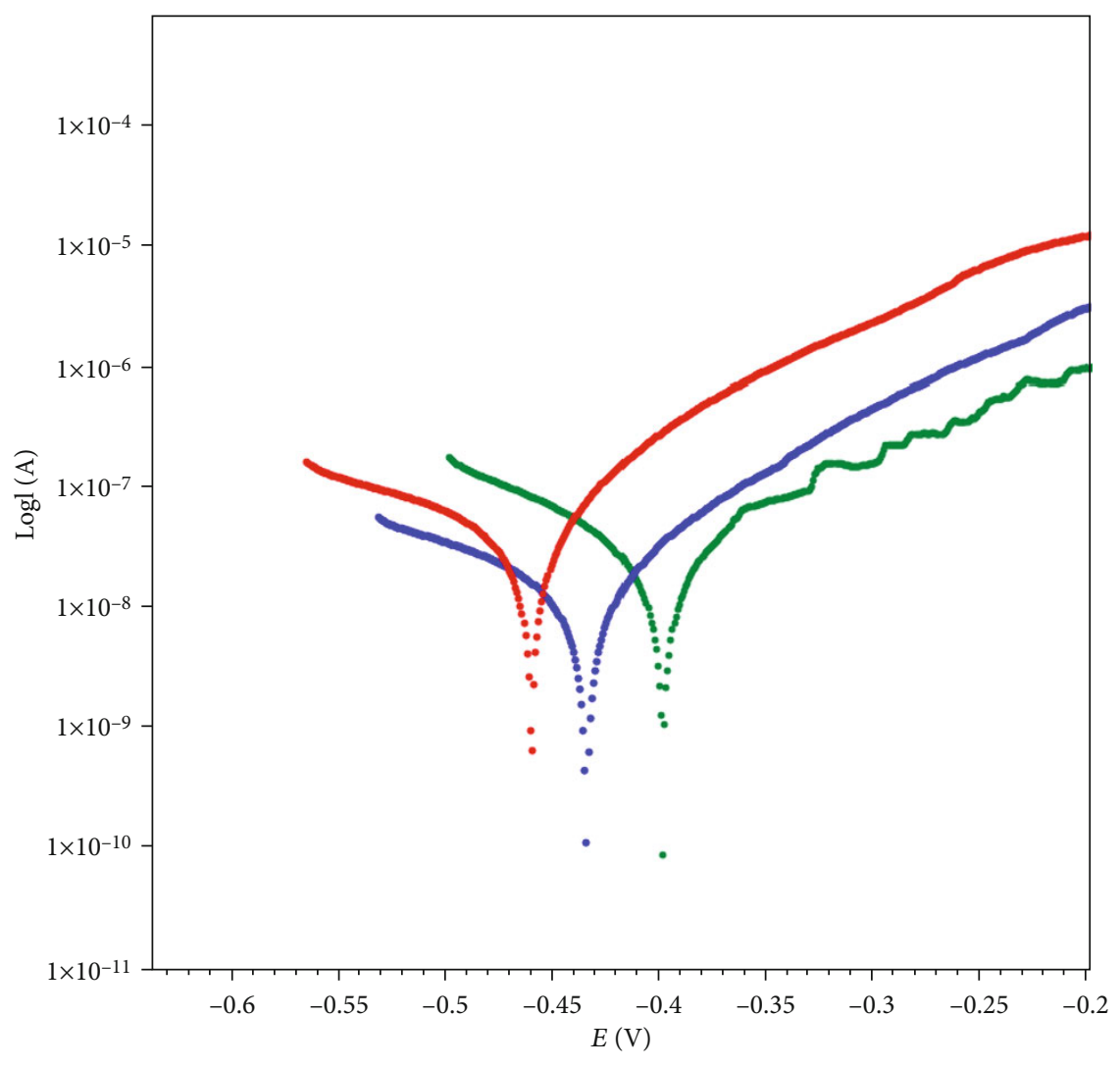

- MCOT

- MCOC

- Control

FIGURE 15: Polarization curves obtained from the control system (red), the MCOC system (dark blue), and the MCOT system (green).

TABle 2: Corrosion potential data, corrosion current density, corrosion rate, and polarization resistance of the unpainted plate, the control, and the systems containing MCOC and MCOT.

\begin{tabular}{lcccc}
\hline Sample & $E_{\text {corr }}(\mathrm{mV})$ & $j_{\text {corr }}\left(\mu \mathrm{A} / \mathrm{cm}^{2}\right)$ & $C_{\mathrm{r}}(\mathrm{mm} /$ year $)$ & $R_{\mathrm{p}}(\mathrm{k} \Omega)$ \\
\hline Control & -531 & $9.00 \times 10^{-3}$ & $1.05 \times 10^{-4}$ & 301 \\
MCOC & -466 & $2.51 \times 10^{-3}$ & $3.16 \times 10^{-5}$ & 815 \\
MCOT & -399 & $2.59 \times 10^{-3}$ & $3.01 \times 10^{-5}$ & 736 \\
\hline
\end{tabular}

Analyzing the polarization resistance values, it is noted that in systems containing microcapsules, there was an increase in the polarization resistance, and since the polarization resistance can be defined as the resistance of the sample to oxidation during the application of an external potential, this indicates greater resistance to corrosion [26].

Finally, when analyzing the corrosion rate data, an industrial parameter of great importance, it is noted that the rate decreases considerably with the addition of microcapsules in the coating. Previous studies by Pontes et al. in 2016 [25] and by Okonkwo et al. in 2015 [27] demonstrated that, for an unprotected sheet exposed in marine environments, the corrosion rate can vary up to $0.6 \mathrm{~mm} /$ year. The value obtained by the control coating confirmed the effectiveness of adding a coating to protect carbon steel, and with the addition of microcapsules, the corrosion rate decreases to values of $3.0 \times 10^{-5} \mathrm{~mm} /$ year, which is equivalent to $30 \mathrm{~nm} /$ year, confirming this protection when adding microcapsules.

From the data obtained by adjusting the polarization curves, it is possible to conclude that the addition of a coating on the carbon steel plate brings anticorrosion protection to the studied system; however, this protection is improved with the addition of microcapsules containing drying oils. When comparing the protection obtained with the addition of copaiba oil microcapsules with those of tung oil microcapsules, the two systems showed similar values in some data; however, in the general analysis, tung oil microcapsules proved to be the most protective against corrosion.

\section{Conclusion}

The present research successfully synthesized microcapsules that contained tung oil and copaiba oil. The morphological analysis concluded that the microcapsule wall is intact without any defects or holes. In addition, due to the polymerization efficiency of urea and formaldehyde monomers in the formation of the PUF, the wall polymer was proven and the formation of microcapsules was verified. By correlating the infrared spectra of the wall material and the core material 
of the microcapsules, a satisfactory encapsulation of the oils by the wall material was confirmed. The granulometry analysis of the sieved microcapsules proved the efficiency of the screening process, obtaining final materials with similar average diameters (between $22 \mu \mathrm{m}$ and $25 \mu \mathrm{m}$ ) and with $95 \%$ of the materials having a diameter less than $50 \mu \mathrm{m}$.

From the OCP results, it was concluded that tung oil was more effective for the system, as it presented the most positive values at the end of the experiment and consequently the best protection over the studied exposure time. Stereoscope images confirmed this conclusion, since over time, the MCOT system was the one that presented the best protection visually.

From the data of the polarization curves and the adjustments, it is concluded that when comparing the protection obtained by the addition of copaiba oil microcapsules with those of tung oil microcapsules, the two systems presented similar values in some data; however, when analyzing in general, tung oil microcapsules proved to be the most protective against corrosion for the studied system.

Although the results between MCOC and MCOT present close values, differentiating between 5 and $10 \%$, it can be said that the resistance provided by the addition of MCOT was more highly expressed when carrying out a global assessment of the results such as OCP evaluation, visual analysis, and polarization curves.

This work focused on a qualitative and comparative analysis of the corrosion protection provided by the addition of the two microcapsules (MCOT and MCOC) in the studied system. To obtain a more concrete confirmation of the microcapsule's mechanisms of action, it is necessary to use nondestructive electrochemical techniques, as in the case of EIS. The group is carrying out work to investigate the mechanism behind the addition of MCOC and MCOT to various coatings.

\section{Data Availability}

The data used to support the findings of this study are available from the corresponding author upon request.

\section{Conflicts of Interest}

The authors declare that they have no conflicts of interest.

\section{References}

[1] V. Gentil, Corrosão, LTC-Livros Técnicos e Científicos Editora S.A., 6 a Ed., 2012.

[2] G. Koch, J. Varney, N. Thompson, O. Moghissi, M. Gould, and J. Payer, "International measures of prevention, application, and economics of corrosion technologies study," NACE International, 2016.

[3] M. L. Zheludkevich, S. K. Poznyak, L. M. Rodrigues et al., "Active protection coatings with layered double hydroxide nanocontainers of corrosion inhibitor," Corrosion Science., vol. 52, no. 2, pp. 602-611, 2010.

[4] M. Behzadnasab, S. M. Mirabedini, M. Esfandeh, and R. R. Farnood, "Evaluation of corrosion performance of a selfhealing epoxy-based coating containing linseed oil-filled microcapsules via electrochemical impedance spectroscopy," Progress in Organic Coatings, vol. 105, pp. 212-224, 2017.

[5] D. O. Grigoriev, K. Köhler, E. Skorb, D. G. Shchukin, and H. Möhwald, "Polyelectrolyte complexes as a "smart" depot for self-healing anticorrosion coatings," Soft Matter, vol. 5, no. 7, pp. 1426-1432, 2009.

[6] V. Sauvant-Moynot, S. Gonzalez, and J. Kittel, "Self-healing coatings: an alternative route for anticorrosion protection," Progress in Organic Coatings, vol. 63, no. 3, pp. 307-315, 2008.

[7] P. P. Vijayan and M. Al-Maadeed, " $\mathrm{TiO}_{2}$ nanotubes and mesoporous silica as containers in self-healing epoxy coatings," Scientific Reports, vol. 6, no. 1, 2016.

[8] D. A. Leal, Síntese E Caracterização De Microcápsulas Com Dupla-Função Contendo Óleo De Linhaça E Benzotriazol Para Aplicação Em Revestimentos Anticorrosivos Inteligentes, Master's Theses. UFPR, Paraná Brazil, 2016.

[9] M. B. Restrepo, Estudo Do Efeito De Autorreparação Nos Revestimentos Aditivados Com Microcápsulas Contendo Óleo De Linhaça. Master's Theses, USP, São Paulo Brazil, 2012.

[10] H. Wang and Q. Zhou, "Evaluation and failure analysis of linseed oil encapsulated self-healing anticorrosive coating," Progress in Organic Coatings, vol. 118, pp. 108-115, 2018.

[11] G. Kurt Çömlekçi and S. Ulutan, "Encapsulation of linseed oil and linseed oil based alkyd resin by urea formaldehyde shell for self-healing systems," Progress in Organic Coatings, vol. 121, pp. 190-200, 2018.

[12] T. Nesterova, K. Dam-Johansen, and S. Kiil, "Synthesis of durable microcapsules for self-healing anticorrosive coatings: a comparison of selected methods," Progress in Organic Coatings, vol. 70, no. 4, pp. 342-352, 2011.

[13] P. Al-Maadeed, "Self-repairing composites for corrosion protection: a review on recent strategies and evaluation methods," Materials, vol. 12, no. 17, p. 2754, 2019.

[14] H. Li, Y. Cui, Z. Li, Y. Zhu, and H. Wang, "Fabrication of microcapsules containing dual-functional tung oil and properties suitable for self-healing and self-lubricating coatings," Progress in Organic Coating, vol. 115, pp. 164-171, 2018.

[15] H. Abdipour, M. Rezaei, and F. Abbasi, "Synthesis and characterization of high durable linseed oil-urea formaldehyde micro/nanocapsules and their self-healing behaviour in epoxy coating," Progress in Organic Coating, vol. 124, pp. 200-212, 2018.

[16] U. D. Bagale, S. H. Sonawane, B. A. Bhanvase, R. D. Kulkarni, and P. R. Gogate, "Green synthesis of nanocapsules for selfhealing anticorrosion coating using ultrasound-assisted approach," Green Processing and Synthesis, vol. 7, no. 2, pp. 147-159, 2018.

[17] A. G. Cordeiro Neto, A. C. Pellanda, A. R. de Carvalho Jorge, J. B. Floriano, and M. A. Coelho Berton, "Preparation and evaluation of corrosion resistance of a self-healing alkyd coating based on microcapsules containing tung oil," Progress in Organic Coatings, vol. 147, p. 105874, 2020.

[18] C. Suryanarayana, K. C. Rao, and D. Kumar, "Preparation and characterization of microcapsules containing linseed oil and its use in self-healing coatings," Progress in Organic Coatings, vol. 63 , no. 1, pp. 72-78, 2008.

[19] M. Samadzadeh, S. H. Boura, M. Peikari, A. Ashrafi, and M. Kasiriha, "Tung oil: an autonomous repairing agent for self-healing epoxy coatings," Progress in Organic Coatings, vol. 70, no. 4, pp. 383-387, 2011. 
[20] K. Thanawala, A. S. Khanna, and R. K. Singh Raman, "Tung oil-urea formaldehyde microcapsules for anti-corrosive selfhealing epoxy coatings," Materials Science \& Surface Engineering, vol. 3, pp. 151-156, 2015.

[21] J. B. Almeida, Desenvolvimento de Filme Magnético Utilizando Maguemita Recoberta com Óleo de Copaíba. Master's Theses, UNB, Brasília Brazil, 2014.

[22] A. R. Souza, D. P. Mota, S. R. D. Paula, S. M. L. Agostinho, and M. M. P. Silva, "Medidas de potencial de circuito aberto: um experimento para o ensino de eletroquímica," in Sociedade Brasileira de Química (SBQ), 32a Reunião Anual da Sociedade Brasileira de Química, 2009.

[23] E. M. Fayyad, M. A. Almaadeed, A. Jones, and A. M. Abdullah, "Evaluation techniques for the corrosion resistance of selfhealing coatings," Int. J. Electrochem Sci, vol. 9, pp. 49895011, 2014.

[24] M. Kouhi, A. Mohebbi, and M. Mirzaei, "Evaluation of the corrosion inhibition effect of micro/nanocapsulated polymeric coatings: a comparative study by use of EIS and Tafel experiments and the area under the Bode plot," Research on Chemical Intermediates, vol. 39, no. 5, pp. 2049-2062, 2013.

[25] J. F. R. Pontes, E. V. Bendinelli, C. da Costa Amorim, M. M. de Sá, and A. P. Ordine, "Effect of corrosion inhibitor used in surface treatment on the anticorrosive performance of an epoxy paint system," Materials Sciences and Application, vol. 7, no. 10, pp. 593-609, 2016.

[26] S. Hiromoto, "Corrosion of metallic biomaterials," in Metals for Biomedical Devices, pp. 99-121, Woodhead Publishing Limited, 2010.

[27] P. C. Okonkwo, A. Shakoor, and A. M. A. Mohamed, "Environmental factors affecting corrosion of pipeline steel: a review," Int. J. of Mechanical and Production Engineering Research and Development, vol. 5, pp. 57-70, 2015. 